\title{
Heat Transfer of Steel in a Slab Tundish with Vacuum Chamber
}

\author{
Jian-an ZHOU, ${ }^{1,2) *}$ Jian-bo XIE, ${ }^{1,2)}$ Bao WANG, ${ }^{1,2)}$ Hong LEI, ${ }^{3)}$ Hua $\mathrm{ZHANG}^{1,2)}$ and Hong-wei $\mathrm{NI}^{1,2)}$ \\ 1) State Key Laboratory of Refractories \& Metallurgy, Wuhan University of Science \& Technology, Hubei, Wuhan, 430081 \\ China. $\quad 2$ ) Key Laboratory of Ferrous Metallurgy and Resources Utilization, Ministry of Education, Wuhan University of \\ Science \& Technology, Hubei, Wuhan, 430081 China. $\quad 3)$ Key Laboratory of Electromagnetic Processing of Materials, \\ Ministry of Education, Northeastern University, Shenyang, 110004 China.
}

(Received on September 14, 2016; accepted on March 2, 2017; J-STAGE Advance published date: April $21,2017)$

\begin{abstract}
For the purpose of reducing the heat loss of steel through the walls of tundish during continuous casting production, a new-type tundish performed by welding radiation-proof steels on its exterior walls was proposed to investigate the effect of the pressure inside a vacuum chamber on the temperature field of steel. Numerical results show that, outlet temperature of vacuum tundish at $50 \mathrm{~Pa}$ is $4 \mathrm{~K}$ higher than that of traditional tundish, and the region of high temperature section is up to $85 \%$ of the whole region when the heat flux through walls is less than $1645 \mathrm{~W} / \mathrm{m}^{2}$. But the region of high temperature section is only $45 \%$ in the traditional tundish. And the maximum temperature difference on the surface is $9 \mathrm{~K}$ lower than that inside the traditional tundish. Tests show that, the temperature of inner point at $10^{2} \mathrm{~Pa}$ is $3 \mathrm{~K}$ higher than that at $10^{5} \mathrm{~Pa}$. Meanwhile, the local temperature difference of outlet at $10^{2} \mathrm{~Pa}$ is $5 \mathrm{~K}$ higher than that at $10^{5} \mathrm{~Pa}$. Vacuum tundish can allow low superheat teeming of steel due to thermal preservation of vacuum so as to decrease the temperature of tapping and improve the uniformity of temperature field of steel. Therefore, this new technology may contribute to applications for continuous casting productions of advanced steel grades.
\end{abstract}

KEY WORDS: tundish; vacuum; pressure; thermal preservation; heat flux.

\section{Introduction}

Temperature of steel strongly affects the quality of casting products and operations of casters. Heat losses of steels in tundish always inevitably occur during the continuous casting production, ${ }^{1)}$ and heat losses specifically come from the melt surface and the walls. But a greater superheat can gravely worsen impurities removal ${ }^{2,3)}$ and result in both segregations ${ }^{4)}$ and the breakouts of mold.

Dating back to the recent 30 years, a number of approaches have been widely proposed in order to keep the temperature fluctuation of steel in a tiny range, especially for the produced requirements of advanced steels. Specifically, these applied methods are mainly divided into two kinds: one is heat preservation and the other is external heating. As is well-known to us, adding fluxes ${ }^{5)}$ and superinducing covers are two useful approaches to reduce heat losses out of the top surface of steel. Chakraborty and Sahai ${ }^{6}$ investigated the effects of various thicknesses of slag layer on the temperature gradients and its stratifications. In addition, the refractories of the tundish are also vital factors in thermal transferring. And it must endure thermal shocks and resist being corrosed. ${ }^{7)}$ Another one is the external heating by means of induction or plasma, which has been widely applied in some companies (e.g., Nippon Steel ${ }^{8)}$ and Kawasaki Steel Corpo-

\footnotetext{
* Corresponding author: E-mail: zhou_jianan@sina.com DOI: http://dx.doi.org/10.2355/isijinternational.ISIJINT-2016-550
}

ration). Kawasaki ${ }^{9)}$ performed an experiment on a tundish of volume 7 tons (the depth of the bath being $600 \mathrm{~mm}$ on full charging). Although the reduction in the temperature in the molten steel in the tundish was thus decreased to an insignificant extent after being performed the various electric powers of the induction heater, the occurrence of the pinching could not be avoided. In addition, the principle of the plasma heating can be described that ionizing inert gas is to form the plasma arc. Matsumoto ${ }^{10)}$ and Iritani ${ }^{11)}$ indicated that the produced efficiency of plasma heating varied from $60 \%$ to $80 \%$, and its temperature fluctuation was less than $5^{\circ} \mathrm{C}$ during the whole operation. A tapping temperature of basic oxygen furnace was decreased by $20^{\circ} \mathrm{C}$. In contrast with plasma, more than $90 \%$ higher thermal efficiency could be obtained on the basis of induction heating ${ }^{12-14}$ ) with a power of $1000 \mathrm{~kW}$. Although there are such benefits mentioned above, the external heating technologies are not further applied by steel companies due to greater costs, the insecurities and the exfoliations of linings. ${ }^{14)}$

Based on the thermal insulation of vacuum, we constructed a new slab tundish ${ }^{15)}$ with a surrounding vacuum chamber to reduce heat losses out of the walls by reducing the pressures. Therefore, this paper is to investigate the effects of the pressures inside vacuum chamber on heat transferring and the temperature field of steel using numerical modeling ${ }^{16-19)}$ and tests based on a single-strand slab tundish. 


\section{Description of Process}

\subsection{Construction of New Tundish}

A traditional tundish consists of the working layer, the permanence layer and the thermal insulation layer. The related physical parameters and dimensions are shown in Tables 1 and 2. However, for the new tundish the constructed process can be described that firstly the surfaces of welded steels (steel I) should be polished and then coated with radiation-proof materials before welding and its chemical components are shown in Table 3. Subsequently, these polished steels are welded on the exterior walls of a traditional tundish to form cavity shells, as shown in Fig. 1. When the cavity is pumped the air out, this cavity shell becomes a vacuum chamber, and then this new tundish is named as a vacuum tundish. When the steel is poured into this new tundish, the heat losses occur from the working layer to the vacuum layer, and then into the air. For the vacuum layer of vacuum tundish, all the inner surfaces of steels inside vacuum chamber are coated with radiationproof materials in order to weaken the thermal radiation inside the vacuum chamber which involves in four-side walls, but not the bottom wall of the tundish.

\subsection{Mathematical Modeling}

The present model is built on the basis of a single-strand slab tundish. The initial teeming temperature is $1802 \mathrm{~K}$.

\subsubsection{Assumption}

1) The molten steel is incompressible, the flow is at a stable state, and the turbulence effect is approximated by the popular $k$ - $\varepsilon$ model. ${ }^{21)}$

2) The effect of top slag on fluid flow is neglected, and the free surfaces in the tundish are assumed to be flat.

3) The heat conduction is at a stable state in the tundish.

4) Heat fluxes of free surfaces and bottom walls are assumed to be the constants. $6,19,20)$

5) The heat transfer of riser vents of vacuum tundish walls can be ignored.

6) The immersed depth of long nozzle is about $250 \mathrm{~mm}$.

\subsubsection{Governing Equations}

For a steady-state incompressible turbulent flow, the mass

Table 1. Parameters of tundish walls

\begin{tabular}{cccc}
\hline Category & Materials & $\begin{array}{c}\text { Thermal conductivity/ } \\
\mathrm{W} \cdot \mathrm{m}^{-1} \cdot \mathrm{K}^{-1}\end{array}$ & $\begin{array}{c}\text { Thickness/ } \\
\mathrm{mm}\end{array}$ \\
\hline $\begin{array}{c}\text { Working layer } \\
\text { Permanence } \\
\text { layer }\end{array}$ & Magnesia brick & $2.1+0.19 \times 10^{-3} \mathrm{~T}$ & 40 \\
$\begin{array}{c}\text { Thermal } \\
\text { insulation layer } \\
\text { Vacuum layer }\end{array}$ & Asbestos board & $0.157+0.19 \times 10^{-3} \mathrm{~T}$ & 20 \\
\hline
\end{tabular}

conservation equation and momentum conservation equations can be written as

Continuity equation:

$$
\frac{\partial\left(\rho u_{i}\right)}{\partial x_{i}}=0
$$

Momentum conservation equation:

$$
\frac{\partial\left(\rho u_{i} u_{j}\right)}{\partial x_{j}}=-\frac{\partial p}{\partial x_{i}}+\frac{\partial}{\partial x_{j}}\left[\mu_{e f f}\left(\frac{\partial u_{i}}{\partial u_{j}}+\frac{\partial u_{j}}{\partial x_{i}}\right)\right]+g_{i}\left(\rho-\rho_{0}\right) \ldots
$$

Energy conservation equation:

$$
\frac{\partial\left(\rho u_{i} C_{p} T\right)}{\partial x_{i}}=\frac{\partial}{\partial x_{i}}\left[\lambda_{\text {eff }} \frac{\partial T}{\partial x_{i}}\right]
$$

\subsubsection{Boundary Conditions and Convergence Criteria}

The symmetric boundary condition is applied at the free surface, the fluid's velocity and temperature at the inlet is the constant, and the boundary condition of outlet pressure is applied at the outlet. Because of the tundish's symmetry, half of the tundish was considered in the present computation. The computational domain was discretized by using a non-uniform grid (about 300000 cells) with a densely packed grid near the nozzle and the wall, as shown in Fig. 2. The grid size is about $1.2 \mathrm{~mm}$, and the parameters of tundish walls and molten steel are shown in Tables 1 and 2 , respectively.

The grid dependence is conducted, and the related grid is $320000,350000,370000$ and 400000 , respectively. The maximum temperature difference at the outlet is less than $0.5 \%$. During the calculation, the wall-function approach is applied in the current paper. The finite volume method was applied to solve these differential equations. During the calculation, the central difference scheme and the upwind scheme are applied to calculate the diffusion term and the convection term, respectively. To avoid divergence in the iterative solution, under-relaxation was employed. With the SIMPLE algorithm proposed by Patankar and Spalding, ${ }^{24)}$ the differential equations were solved by iteration until the residual error of the mass source term was less than $10^{-5}$.

Heat fluxes of the traditional tundish walls are obtained on the basis of the recommended values by Chakraborty and

\begin{tabular}{|c|c|c|c|}
\hline Parameters & steel & Parameters & steel \\
\hline Density $/\left(\mathrm{kg} \cdot \mathrm{m}^{-3}\right)$ & $\begin{array}{l}8524- \\
0.8351 T\end{array}$ & Heat capacity $/\left(\mathrm{J} \cdot \mathrm{kg}^{-1} \cdot \mathrm{K}^{-1}\right)$ & 652 \\
\hline Viscosity/(Pa·s) & 0.0064 & Inflation coefficient/( $\left.\mathrm{K}^{-1}\right)$ & $10^{-4}$ \\
\hline $\begin{array}{l}\text { Velocity of inlet/ } \\
\left(\mathrm{m} \cdot \mathrm{s}^{-1}\right)\end{array}$ & 1.98 & $\begin{array}{l}\text { Thermal conductivity/ } \\
\qquad\left(\mathrm{W} \cdot \mathrm{m}^{-1} \cdot \mathrm{K}^{-1}\right)\end{array}$ & 41.2 \\
\hline $\begin{array}{l}\text { Inner diameter of the } \\
\text { long nozzle } /(\mathrm{mm})\end{array}$ & 50.0 & $\begin{array}{c}\text { Inner diameter of the submerged } \\
\text { entry nozzle } /(\mathrm{mm})\end{array}$ & 70.0 \\
\hline
\end{tabular}
Sahai. ${ }^{6,19,20)}$ The heat fluxes are the constants in the cases of

Table 2. Properties of molten steel.

Table 3. The main chemical components of steel (mass $\%)$.

\begin{tabular}{ccccccccccccccc}
\hline group & C & Mn & Si & P & S & Al & Nb & V & Ti & Cr & Ni & Mo \\
\hline Steel I & $\leq 0.18$ & $\leq 1.70$ & $\leq 0.50$ & $\leq 0.025$ & $\leq 0.02$ & $\geq 0.015$ & $\leq 0.07$ & $\leq 0.15$ & $\leq 0.2$ & $\leq 0.3$ & $\leq 0.012$ & $\leq 0.1$ \\
Steel II & $\leq 0.17$ & $\leq 1.4$ & $\leq 0.35$ & $\leq 0.035$ & $\leq 0.035$ & & & & & & & & & \\
\hline
\end{tabular}




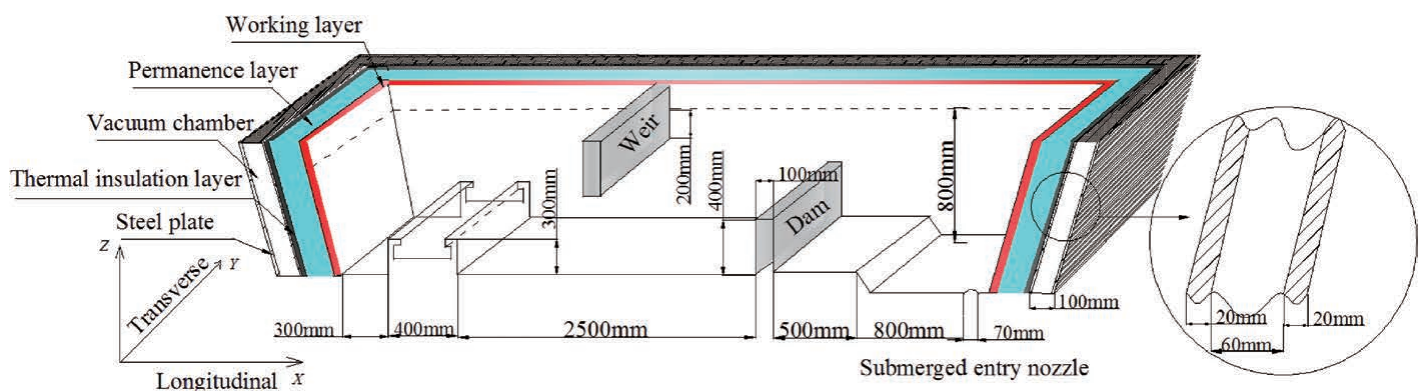

Fig. 1. Structure devices and modeling parameters of vacuum tundish.

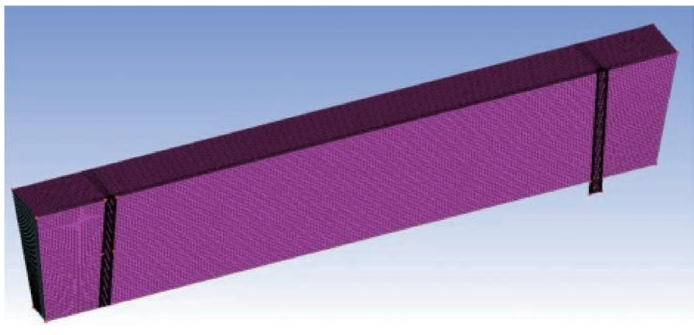

Fig. 2. Computational mesh.

the walls such as, the bottom $\left(1400 \mathrm{~W} \cdot \mathrm{m}^{-2}\right)$ and the melt surface $\left(15000 \mathrm{~W} \cdot \mathrm{m}^{-2}\right)$. But they are changed under the vacuum chamber with a lower pressure condition. Different vacuum pressures result in various heat fluxes through the walls. $\left.{ }^{23}\right)$ This idea is therefore valuable. The heat fluxes were achieved by the tests and the numerical simulations, as shown in Fig. 3.

\subsubsection{Heat Flux in the Vacuum Chamber}

Obtaining the gaseous contribution to the thermal conduction may be hard because it is dependent on the composition and pressure of the contained gas. For most gases at pressures above $1 \mathrm{~Pa}$, thermal conductivity is mainly a function of temperature, ${ }^{22)}$ and cryogenics formulae cannot be suitable for high pressures. Therefore, $\mathrm{Na}^{23)}$ proposed a calculated approach. At medium or low vacuum pressures, thermal conductivity $\lambda$ inside vacuum chamber can be expressed by:

$$
q=-\lambda \frac{d T}{d x}
$$

Here, $\lambda$ consists of thermal conduction, convection and radiation in the vacuum chamber.

$$
\begin{gathered}
\lambda=\lambda_{1}\left(1+\varepsilon_{\mathrm{k}}\right)+\lambda_{2} \ldots . \\
4 \lambda_{1}=\mu(9-5 \gamma) C_{\mathrm{V}} \ldots . \\
\varepsilon_{\mathrm{k}}=0.062\left[\frac{g \beta}{v \alpha}\right]^{\frac{1}{3}} \Delta T^{\frac{1}{3}} \delta L
\end{gathered}
$$

Meanwhile, the equivalent thermal conduction for radiation is

$$
Q_{1}=-\lambda_{2} \frac{\partial T}{\partial x} A
$$

And the radiation formulae $\mathrm{e}^{22)} \mathrm{of}$ high and low temperature

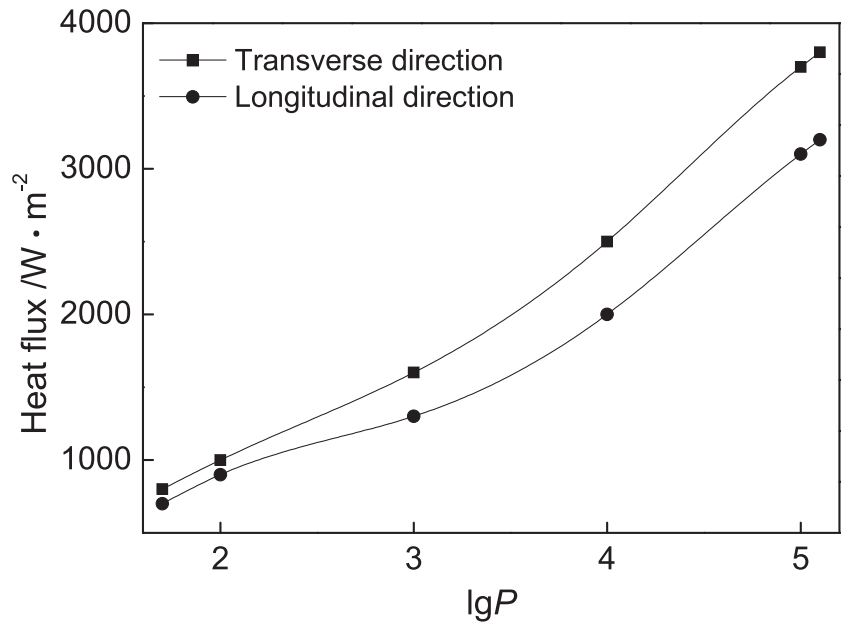

Fig. 3. Heat flux of steel in both directions.

sides can be expressed as Eqs. (9) and (10).

$$
\begin{gathered}
Q_{2}=h_{1}\left(T_{\mathrm{a}}-T_{\mathrm{b}}\right) A \ldots \ldots . . . \\
h_{1}=\frac{\sigma_{0}\left(T_{\mathrm{a}}^{4}-T_{\mathrm{b}}^{4}\right)}{\left(T_{a}-T_{b}\right)\left(\frac{1}{\varepsilon_{1}}+\frac{1}{\varepsilon_{2}}-1\right)} .
\end{gathered}
$$

If Eqs. (9) and (10) are substituted by Eq. (8), we will get

$$
\lambda_{2}=\frac{\sigma_{0}\left(T_{\mathrm{a}}^{4}-T_{\mathrm{b}}^{4}\right) \delta}{\left(\frac{1}{\varepsilon_{1}}+\frac{1}{\varepsilon_{2}}-1\right) \Delta T}
$$

\section{Results and Discussion}

\subsection{Temperature Distribution of Free Surface in Vac- uum Tundish}

When the molten steel from a ladle is poured into the vacuum tundish, the fluid flow is the turbulent flow and the region with high temperature ( $1802 \mathrm{~K}$ ) around the long nozzle is as shown in Fig. 4. Hotter steel occupies the majority of inlet region whose temperature is higher than that of any other region. Due to the greater thermal loss, the high temperature region could not diffuse fully and reach the submerged entry nozzle appropriately. As a result, this region has a lowest temperature of $1775 \mathrm{~K}$ at the boundary, and the maximum temperature difference reaches $27 \mathrm{~K}$. It should be noted that the thermal loss of walls decreases and high temperature region is enlarged with decreasing pressures. As a result, the surface temperature above the submerged entry nozzle at $10^{2} \mathrm{~Pa}$ is $6 \mathrm{~K}$ higher than that at traditional 
tundish. We define the region where the temperature is less than $1790 \mathrm{~K}$ as an inaction region. Such regions are always located near the boundary. The inaction region of vacuum tundish has a lowest temperature of $1787 \mathrm{~K}$ at $10^{4} \mathrm{~Pa}$. And with decreasing vacuum pressure, the maximum temperature difference only reduces by $4 \mathrm{~K}$ in the case of pressure below $10^{3} \mathrm{~Pa}$. Several reasons lead to this interesting phenomenon. (1) The thermal loss at side walls decrease with decreasing the vacuum pressure. (2) The thermal buoyancy of molten steel decreases near the outlet due to the higher temperature of the side wall. (3) It is easier for the hotter molten steel from shroud to enter the region near the outlet

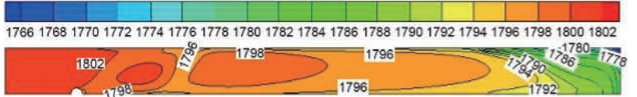

(a) Traditional tundish

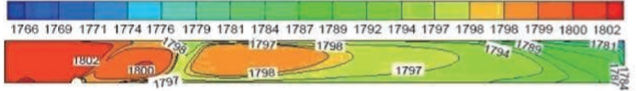

(c) $10^{4} \mathrm{~Pa}$

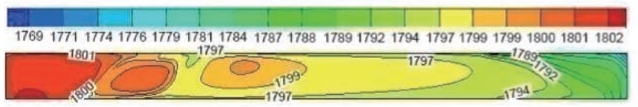

(e) $10^{2} \mathrm{~Pa}$

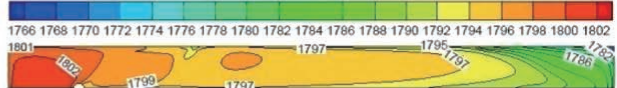

(b) $10^{5} \mathrm{~Pa}$

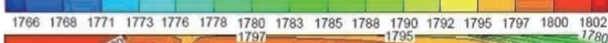

1802

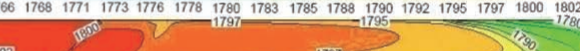

(d) $10^{3} \mathrm{~Pa}$

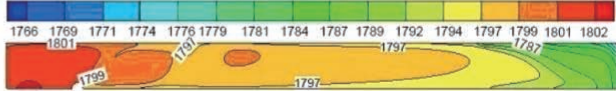

(f) $50 \mathrm{~Pa}$

Fig. 4. Temperature distribution isolines of tundish free surface.

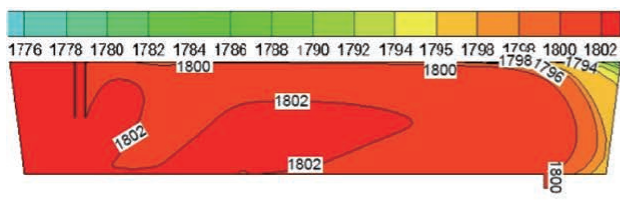

(a) Traditional tundish

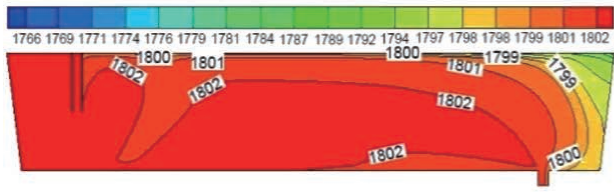

(c) $10^{4} \mathrm{~Pa}$

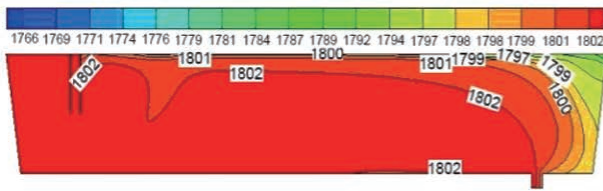

(e) $10^{2} \mathrm{~Pa}$

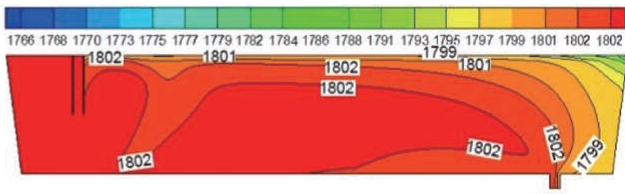

(b) $10^{5} \mathrm{~Pa}$

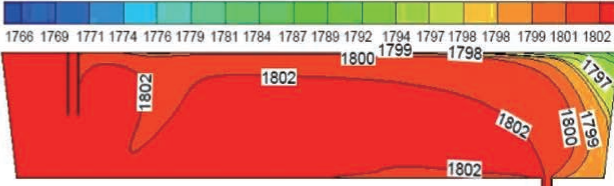

(d) $10^{3} \mathrm{~Pa}$

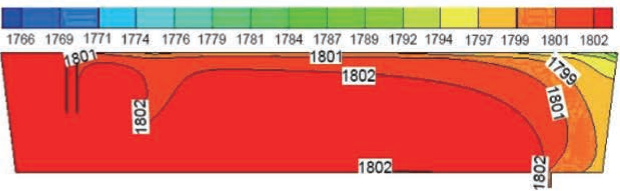

(f) $50 \mathrm{~Pa}$

Fig. 5. Distribution isolines of longitudinal temperature in tundish.

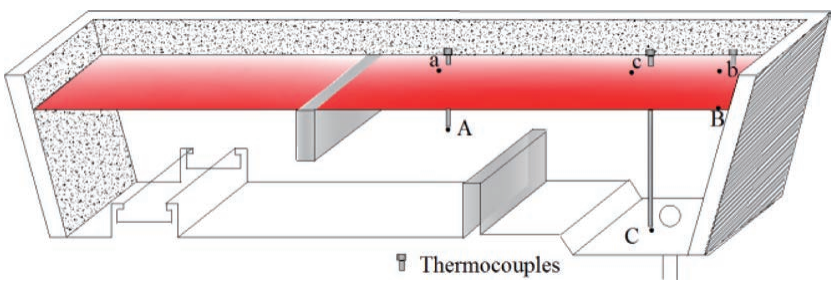

Fig. 6. Measured temperatures along the central plane in a vacuum tundish. A-Center of the surface between weir and dam; B-Edge surface point near the longitudinal walls; C-Inner measured point of outlet.

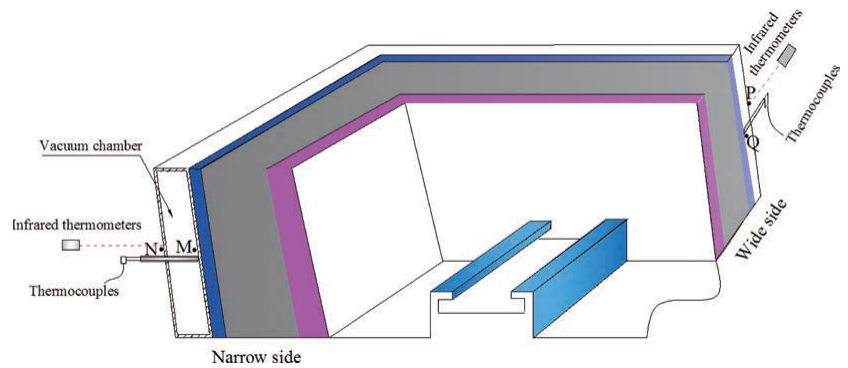

Fig. 8. Measured temperature of vacuum layer. 
because of the weaker resistance (thermal buoyancy).

\subsection{Temperature Distributions Inside Vacuum Tundish}

Figure 5 shows that, with decreasing vacuum pressures, annular isotherms of high temperature in vacuum tundish continue to spread, and then the area of high temperature section is enlarged, resulting in the temperature gradient of molten steel and inaction region with low temperature decreased. As a result, the outlet temperature of vacuum tundish at $10^{3} \mathrm{~Pa}$ is $3 \mathrm{~K}$ higher than that at traditional tundish. And the inaction section of molten steel at traditional tundish has the lowest temperature of $1792 \mathrm{~K}$, while vacuum tundish at $10^{4} \mathrm{~Pa}$, has the lowest temperature of $1797 \mathrm{~K}$. Therefore, the maximum temperature difference reaches $10 \mathrm{~K}$ and $5 \mathrm{~K}$, respectively. Then the maximum temperature difference is also further decreased with decreasing pressures. And the temperature fields are similar at $10^{3} \mathrm{~Pa}, 10^{2} \mathrm{~Pa}$ and $50 \mathrm{~Pa}$, which is beneficial to the continuous casting in actual productions. Conversely, the temperature of inaction region is increased and section area of high temperature $(1802 \mathrm{~K})$ around the submerged entry nozzle is smaller at $10^{5} \mathrm{~Pa}$ than that of any other pressure.

\subsection{Measured Temperatures of Steel}

The processes of tests can be expressed that: firstly, we opened the valves, and pumped the air in the vacuum chamber out using mechanical vacuum pumps, and then kept the pressures stable. Secondly, after the pressure-keepings, the temperatures of steel are measured when steel is poured into the testing tundish. And its temperatures are recorded on the computer. Testing devices include mechanical vacuum pumps, thermocouples, infrared thermometers.

The testing absolute pressures in the chamber during the total tests are set to $10^{2} \mathrm{~Pa}, 10^{3} \mathrm{~Pa}, 10^{4} \mathrm{~Pa}$ and $10^{5} \mathrm{~Pa}$, respectively. And the monitored points $(\mathrm{A}, \mathrm{B}$ and $\mathrm{C})$ are set along the central longitudinal side as shown in Fig. 6. The casting period is $30 \mathrm{~min}$, and the initial teeming temperature is $1816 \mathrm{~K}$. The measured temperatures were recorded every $5 \mathrm{~min}$. The average cooling rate of "steel II " at inlet is $0.6^{\circ} \mathrm{C} / \mathrm{min}$.

The position of point $\mathrm{A}$ is the center point of the steel surface between the weir and the dam and its inserted depth is about $100 \mathrm{~mm}$. The position of point $\mathrm{B}$ is the center point of the steel surface near the walls of narrow side below and its inserted depth is about $100 \mathrm{~mm}$. And the position of point $\mathrm{C}$ is the center point of the inner steel near the submerged entry nozzle below and its inserted depth is about $700 \mathrm{~mm}$. The long nozzle is on the left side of the tundish in Fig. 6.

Figure 7 shows that the temperature of steel increases by reducing pressure. The temperature of point $\mathrm{A}, \mathrm{B}$ and $\mathrm{C}$ at $10^{2} \mathrm{~Pa}$ is $3 \mathrm{~K}, 10 \mathrm{~K}$ and $5 \mathrm{~K}$ higher than that at $10^{5}$ $\mathrm{Pa}$, respectively. The conclusion can be made that a lower pressure inside the vacuum chamber can be beneficial to reducing the temperature oscillations and the temperature gradients of steel in tundish.

\subsection{Measured Temperatures of Vacuum Layer}

Figure 8 indicates the measured locations of temperature. $T_{\mathrm{M}}, T_{\mathrm{N}}, T_{\mathrm{Q}}$ and $T_{\mathrm{P}}$ represent the temperature of points $M, N$, $Q$ and $P$, respectively. A couple of central spots of the walls are used to regard as measured points of temperature for the
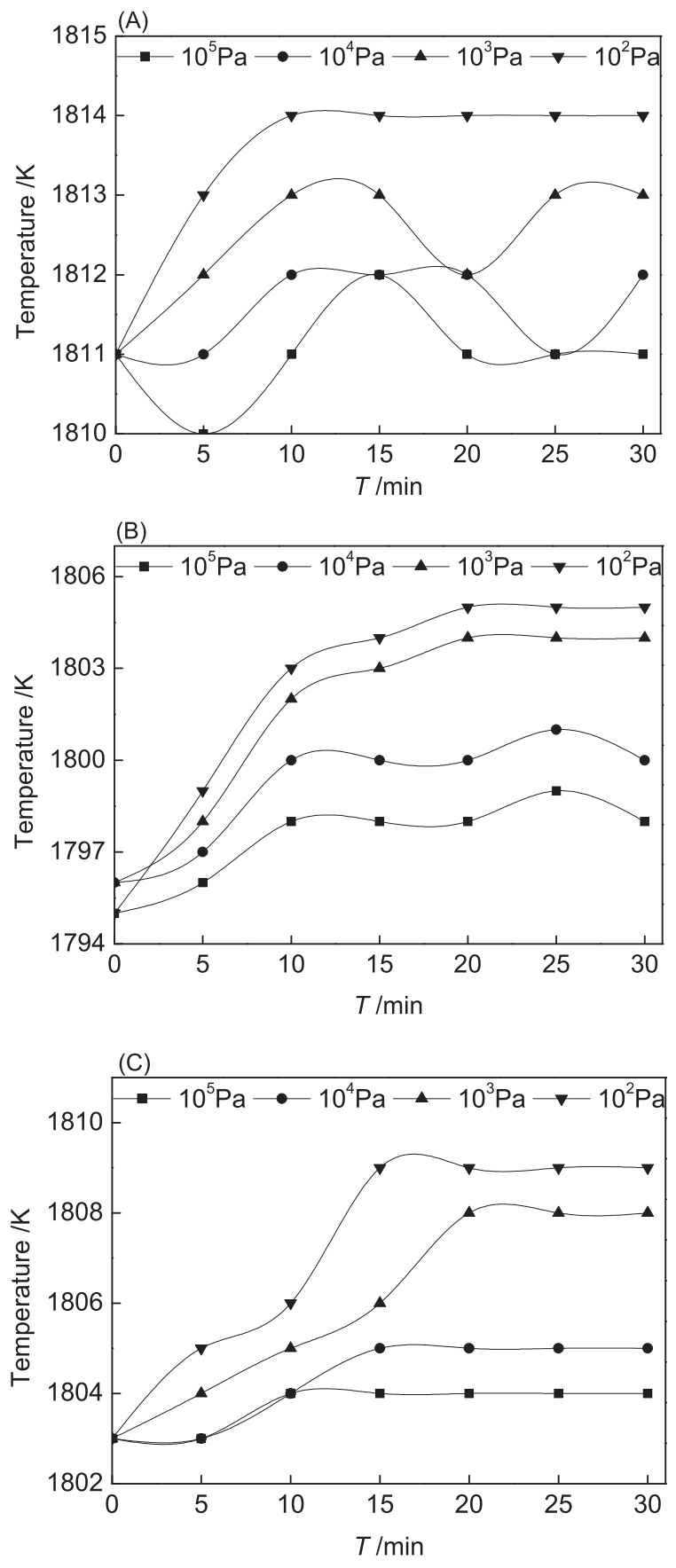

Fig. 7. Test temperatures evolution with various pressures.

vacuum layer. There are small holes remained for testing measurements of the walls, and the steel pipes configured with the thermocouples were fixed at these holes. For the purpose of overcoming the defects out of the air molecules, we use the refractory fibers to stuff the pore where it is located between the steel pipe and thermocouple. Once we began to conduct the tests, the temperatures inside the inner vacuum chamber and at the outer wall were obtained using thermocouples and using infrared thermometers, respectively.

Figure 9 indicates the relationship of the temperature evolutions and various pressures. And the temperatures are obtained at steady states. In the case of increasing pressures, $T_{\mathrm{M}}$ and $T_{\mathrm{Q}}$ are reduced while $T_{\mathrm{N}}$ and $T_{\mathrm{P}}$ are increased. Under a certain pressure condition, $T_{\mathrm{M}}$ is higher than $T_{\mathrm{Q}}$ 

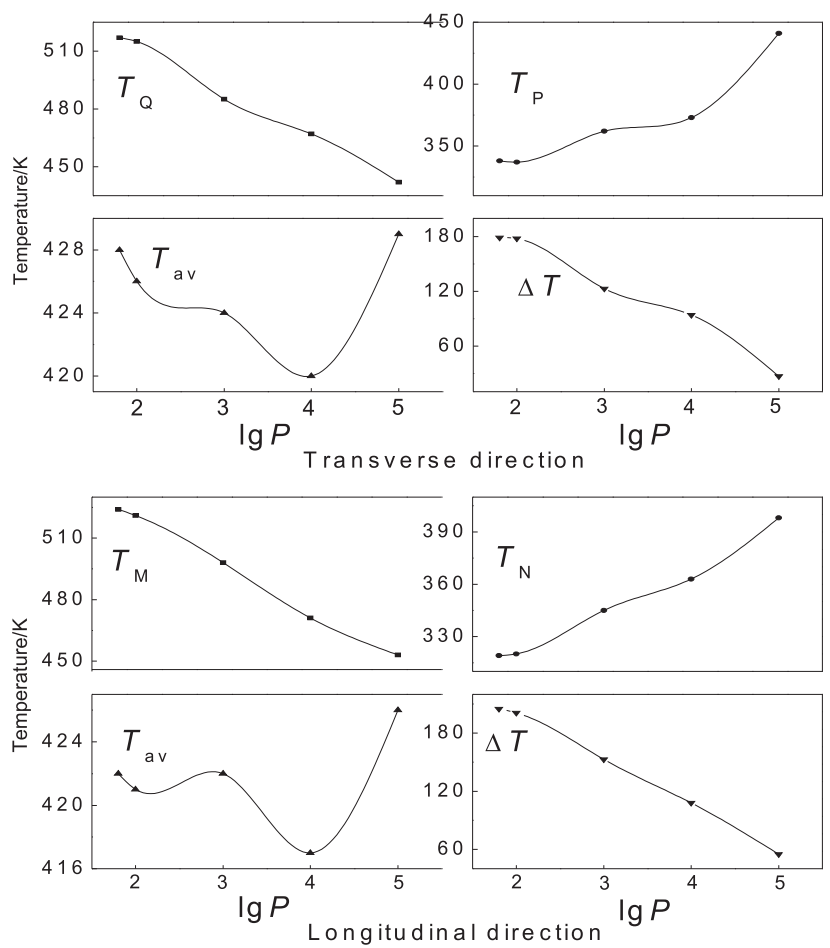

Fig. 9. Temperature evolution with the pressure.

because the heat loss is always greater in the transverse wall than the longitudinal wall, combined with the views from Chakraborty and Sahai. ${ }^{6,19,20)}$ In addition, $T_{\mathrm{P}}$ is greater than $T_{\mathrm{N}}$. Because the higher the temperature is, the greater its thermal conduction and radiation flux are. In the case of increasing pressures, the variations of $T_{\mathrm{av}}$ in both directions decrease, and its value remained at $420 \mathrm{~K} . \Delta T$ in both directions are reduced in the case of increasing pressures, while its value is $30 \mathrm{~K}$ higher in the longitudinal wall than the transverse wall. The phenomenon shows that heat loss is greater in the transverse wall than the longitudinal wall.

\subsection{Heat Flux of Vacuum Layer}

For the purpose of obtaining behaviors of heat transferring, the temperatures in Fig. 9 are applied to calculate the heat fluxes. Combined with Eq. (4), the heat fluxes are obtained in Fig. 10.

Figure 10 shows that heat flux increases in the case of increasing pressure. When the pressure is set to $10^{5} \mathrm{~Pa}$, the heat flux is on the order of $2950 \mathrm{~W} / \mathrm{m}^{2}$ in the longitudinal direction and $3050 \mathrm{~W} / \mathrm{m}^{2}$ in the transverse direction, respectively. While for a traditional tundish the heat flux is estimated at $3200 \mathrm{~W} / \mathrm{m}^{2}$ in the longitudinal direction and $3800 \mathrm{~W} / \mathrm{m}^{2}$ in the transverse direction, respectively. Remarkably, the heat fluxes at $10^{5} \mathrm{~Pa}$ in both directions are slightly smaller than those of a traditional tundish at atmospheric pressure due to thermal insulation of warm air. However, the heat fluxes at less than $10^{3} \mathrm{~Pa}$ are far smaller in the longitudinal and transverse directions than those at atmospheric pressure due to the stronger thermal insulation, which is more conducive to thermal insulation.

At $5 \mathrm{~min}$, the heat flux at $10^{5} \mathrm{~Pa}$ is always smaller than that at $10^{2} \mathrm{~Pa}$, while at $30 \mathrm{~min}$, the heat flux is nearly 4 times greater at $10^{5} \mathrm{~Pa}$ than at $10^{2} \mathrm{~Pa}$. Such a weird appear- (a) Transverse direction

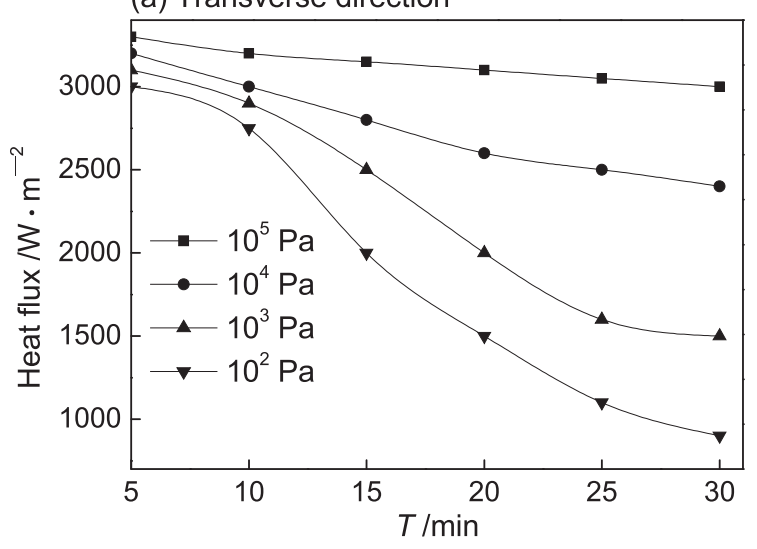

(b) Longitudinal direction

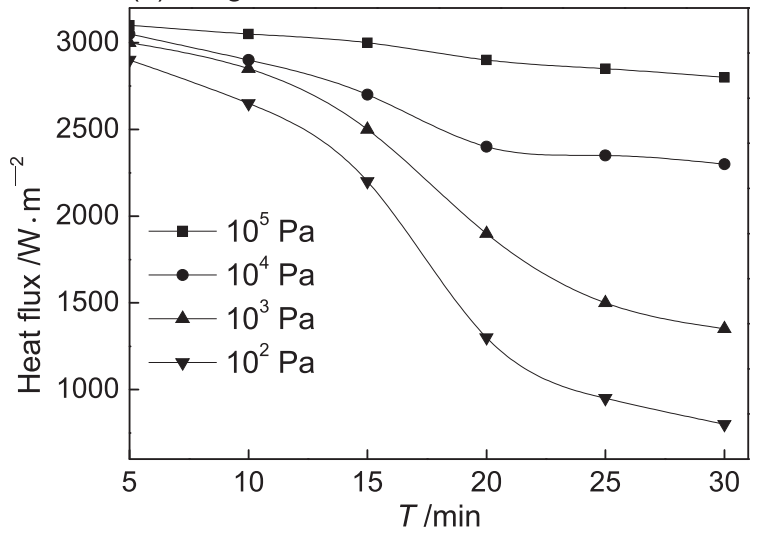

Fig. 10. The evolution of heat fluxes inside vacuum chamber.

ance can be expressed that: under lower pressures condition, small amount of air molecules can lead to weaker convection of gas. Over time, the temperatures inside vacuum chamber increase due to continuous thermal transferring from molten steel, which exerts a greater increase of convection motion and thermal conduction. Therefore, the heat flux at a higher pressure increases much faster than that at a lower pressure.

\subsection{Thermal Coefficients of the Walls}

Figure 11 indicates the relationship of thermal coefficients, pressures and time. Figure 11(A) indicates that by increasing pressures, thermal conductivities are slowly increased in the vacuum chamber as the thermal conduction of air is not influenced by the pressure but by the temperature. ${ }^{25)}$ Figure 11(B) shows that, conversion radiation coefficient stays in a narrow range because of polished steels coated with radiation-proof materials. Figure 11(C) indicates that, with the time, the pressure has a strong effect on the conversion convection additional factor. And its factor value is over 100 times larger at $10^{5} \mathrm{~Pa}$ than at $10^{2} \mathrm{~Pa}$ but this factor is not influenced by the temperature.

Figure 12 indicates the relationship of thermal conductivities between vacuum layer and the walls. The thermal conductivities of the walls are increased over time. Table 2 indicates that the thermal conductivities of the refractories are linear functions with the temperature. Higher temperatures result in the greater thermal conductivities of the refractories. 
(A)
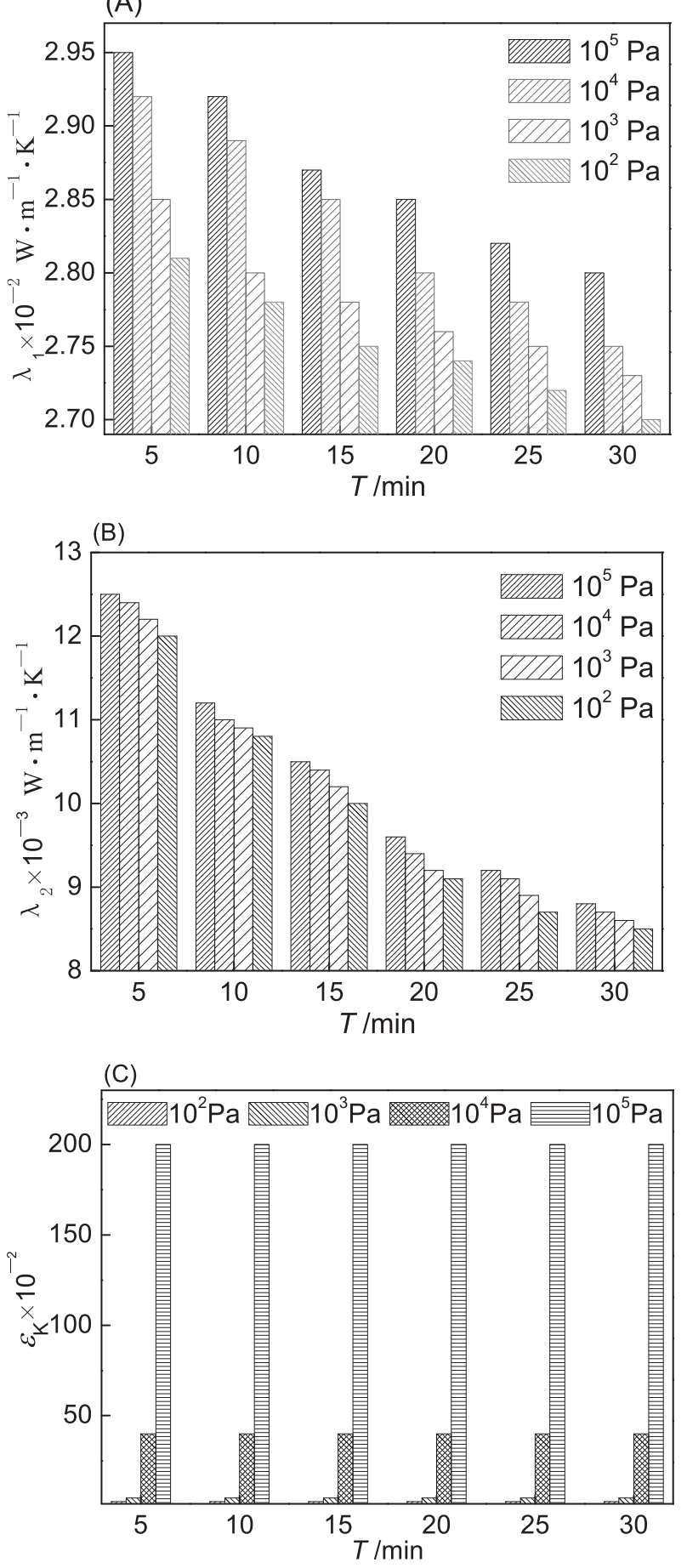

Fig. 11. The thermal coefficients evolution with the pressure and time.

Figure 12(D) indicates that the comprehensive thermal conductivity of vacuum layer is controlled by the pressure. And its conductivity is small at a low pressure while it is large at a high pressure. However, convection effect is strongly affected by the temperature and over time the temperature is increased before reaching the steady state of the thermal transferring from the hotter steel. Thus, the thermal conductivities of the walls and vacuum layer increase with the time before reaching the steady state, as can be seen in Figs. 12(D) and 12(E).

Of all, the thermal conductivity of working layer is the largest, while vacuum layer is the smallest. Thermal
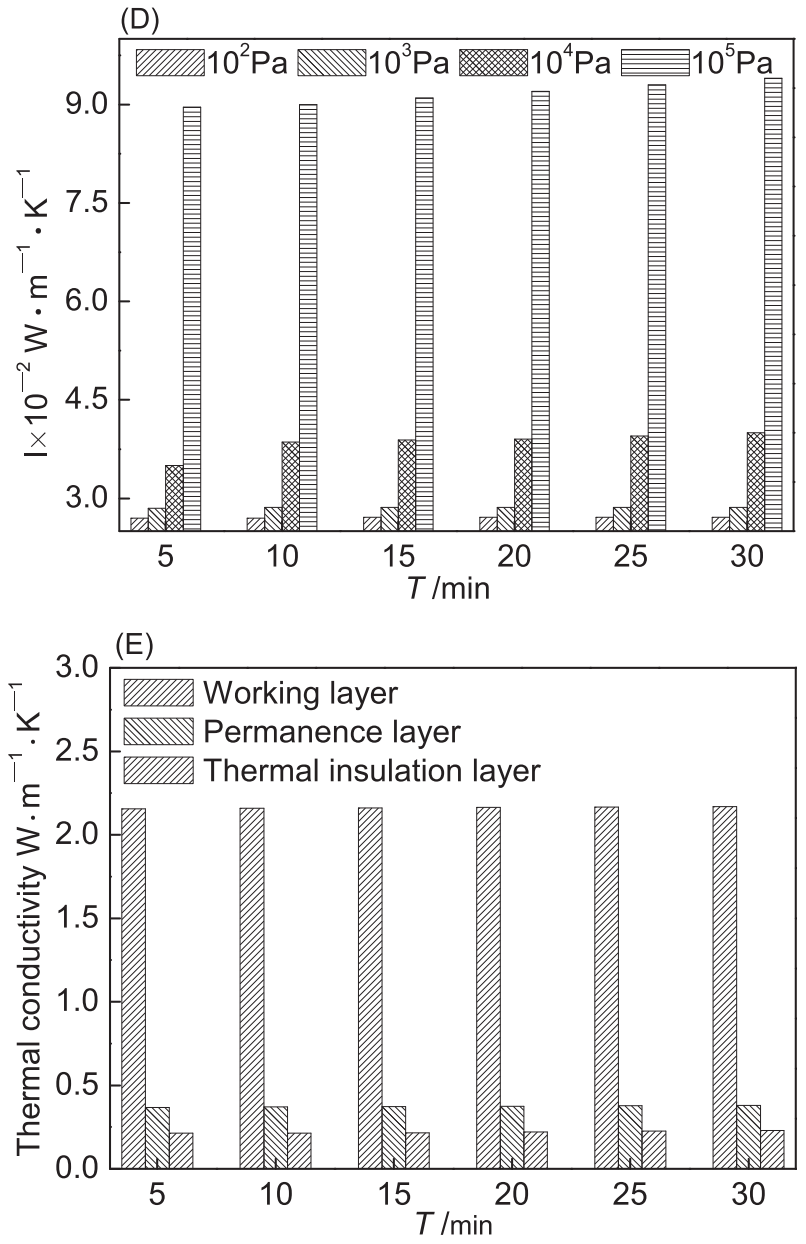

Fig. 12. The thermal conductivity comparison between the walls and vacuum layer.

conductivity of thermal insulation layer is 2 times greater than that of vacuum layer at $10^{5} \mathrm{~Pa}$. Furthermore, thermal conductivity of thermal insulation layer is 11 times larger than that of vacuum layer at $10^{2} \mathrm{~Pa}$. Thus, vacuum layer has strong abilities of thermal insulation under the lower pressures conditions.

\section{Conclusions}

Numerical simulations and tests are applied to investigate the heat transferring in the vacuum tundish.

(1) Numerical simulations indicate that the lower pressure can contribute to the more uniformity of temperature field of the steel due to the lesser heat loss.

(2) Tests show that steel with a low pressure inside vacuum tundish has less temperature gradient. The temperature of point $\mathrm{A}, \mathrm{B}$ and $\mathrm{C}$ at $10^{2} \mathrm{~Pa}$ is $3 \mathrm{~K}, 10 \mathrm{~K}$ and $5 \mathrm{~K}$ higher than that at $10^{5} \mathrm{~Pa}$, respectively. The conclusion can be made that a lower pressure inside the vacuum chamber can be beneficial for reducing the temperature oscillations and the temperature gradients of steel in tundish.

(3) Thermal coefficients of vacuum tundish are far less than those of traditional tundish. Vacuum tundish can achieve low superheat teeming of steel, which is more conducive to producing advanced steel grades.

(4) As for actual productions, the pressure in the chamber is suggested to be $50 \mathrm{~Pa}-10^{2} \mathrm{~Pa}$. 


\section{Symbol List}

$\lambda$-Comprehensive thermal conductivity, $\mathrm{W} \cdot \mathrm{m}^{-1} \cdot \mathrm{K}^{-1}$; $\lambda_{1}-$ Thermal conductivity, $\mathrm{W} \cdot \mathrm{m}^{-1} \cdot \mathrm{K}^{-1}$;

$\lambda_{2}-$ Conversion thermal conductivity of radiation, $\mathrm{W} \cdot \mathrm{m}^{-1}$. $\mathrm{K}^{-1}$;

$\rho_{0}-$ Original density of steel, $\mathrm{kg} \cdot \mathrm{m}^{-3}$;

$\varepsilon_{\mathrm{k}}$-Conversion thermal conductivity of convection;

$\gamma$ Air thermal insulation exponential, 1.403;

$p$-Absolute pressure, $\mathrm{Pa}$;

$L$ - Qualitative size, $\mathrm{m}$;

$\delta$-Characteristic length, $\mathrm{m}$;

$x_{i}-$ Coordinates of $x^{-}, y^{-}$and $z^{-}$direction;

$v$ - Kinematic viscosity, $\mathrm{m}^{2} \cdot \mathrm{s}^{-1}$;

$\mu$ - Air viscosity, $\mathrm{Pa} \cdot \mathrm{s}$;

$\Delta T$-Temperature difference, $\mathrm{K}$;

$T_{\mathrm{av}}-$ Average temperature of vacuum chamber, $\mathrm{K}$;

$T_{\mathrm{a}}-$ High temperature of vacuum chamber, $\mathrm{K}$;

$T_{\mathrm{b}}$ - Low temperature of vacuum chamber, $\mathrm{K}$;

$\delta$-Distance between high and low temperature side inside vacuum chamber, $\mathrm{mm}$;

$g_{\mathrm{i}}$ - Gravitational acceleration of $x^{-}, y^{-}$and $z^{-}$direction, $\mathrm{m} \cdot \mathrm{s}^{-2}$

$\sigma_{0}-$ Stefan Boltzmann constant, $\mathrm{W} \cdot \mathrm{m}^{-2} \cdot \mathrm{K}^{-1}$;

$A$-Area of parallel steel plates, $\mathrm{m}^{2}$;

$\mu_{\text {eff }}$-Effective dynamic viscosity, $\mathrm{Pa} \cdot \mathrm{s}$;

$\varepsilon$-Emissivity of radiation proof steel plates;

$\beta$-Volumetric thermal expansion coefficient, $\beta=1 / T_{\mathrm{m}}$;

$T$-Temperature, K;

$Q_{1}$ - Amount of thermal conduction, W;

$Q_{2}-$ Amount of radiation, W;

$q$ - Heat flux, $\mathrm{W} \cdot \mathrm{m}^{-2}$;

$h_{1}$ - Coefficient of thermal transfer, $\mathrm{W} \cdot \mathrm{m}^{-2} \cdot \mathrm{K}^{-1}$;

$\mathrm{Cv}$-Constant volume specific heat of air, $\mathrm{kJ} \cdot \mathrm{kg}^{-1} \cdot \mathrm{K}^{-1}$, $C v=0.717 \times\left(1+3.45 \times 10^{-5} \times T_{\mathrm{m}}\right)$;

$u_{\mathrm{j}}, u_{\mathrm{i}}-$ Velocities of $x^{-}, y^{-}$and $z^{-}$direction, $\mathrm{m} / \mathrm{s}$;

$\rho$-Density of steel, $\mathrm{kg} \cdot \mathrm{m}^{-3}$;

$\lambda_{\text {eff }}-$ Effective thermal conductivity, $\mathrm{W} \cdot \mathrm{m}^{-1} \cdot \mathrm{K}^{-1}$

\section{REFERENCES}

1) Y. Sahai and T. Emi: Tundish Technology for Clean Steel Production, World Scientific Publishing, Singapore, (2008), 156.

2) J. Strandh, K. Nakajima, R. Eriksson and P. Jonsson: ISIJ Int., 45 (2005), 1597.

3) H. Arcos-Gutierrez, J. de J. Barreto, S. Garcia-Hernandez and A. Ramos-Banderas: J. Appl. Math., 2012 (2012), 3800.

4) I. Suzuki, S. Noguchi, Y. Kashiwakura, T. Horie and M. Saito: 71st Steelmaking, Conf., Iron \& Steel Society, Warrendale, PA, (1988), 125.

5) P. C. Yan, S. Arnout, M.-A. Van Ende, E. Zinngrebe, T. Jones, B. Blanpain and M. Guo: Metall. Mater. Trans. B, 46 (2015), 1242.

6) S. Chakraborty and Y. Sahai: Metall. Trans. B, 23 (1992), 135.

7) J. A. Dody, J. Rumpeltin and R. Charles: Lightweight Sprayable Tundish Lining Composition, Patent of US, 5602063, (1997).

8) S. Ikehara, Y. Terada, S. Kubo and J. Sakuragi: Nippon Steel Tech. Rep., 70 (1996), 55

9) Y. Yoshii, T. Nozaki, Y. Habu, T. Ueda, A. Harita and M. Sakurai: Tetsu-to-Hagané, 71 (1985), 1474.

10) K. Matsumoto, Y. Hoshijima, K. Ishikura, K. Umezawa, Y. Nuri and Y. Ohori: Proc. 6th Int. Iron Steel Cong., ISIJ, Tokyo, (1990), 222.

11) H. Iritani, T. Saito and H. Fujimoto: Proc. 6th Int. Iron Steel Cong., ISIJ, Tokyo, (1990), 230

12) J.-F. Fan, J.-X. Lu and J.-J. Liu: Acta Metall. Sin., 37 (2001), 429

13) J. Barreto-Sandoval, A. Hills, M. Barron-Meza and R. Morales: ISIJ Int., 36 (1996), 1174.

14) M. A. Barron-Meza, J. de J. Barreto-Sandoval and R. D. Morales: Metall. Mater. Trans. B, 31 (2000), 63.

15) J.-A. Zhou, P. Zhou and X. Li: One Metallurgical Container with Vacuum Device, Patent of China, 201110054782. 3, (2012).

16) K. Chattopadhyay, M. Isac and R. Guthrie: ISIJ Int., 50 (2010), 331.

17) M.-J. Zhang, H.-Z. Gu, A. He, H.-X. Zhu and C.-J. Deng: J. Min. Metal. Sect. B-Metall., 47 (2011), 137.

18) K. Takahashi, M. Ando and T. Ishii: ISIJ Int., 54 (2014), 304.

19) T.-P. Qu, C.-J. Liu and M.-F. Jiang: J. Iron Steel Res., Int., 19 (2012), 12 .

20) S. Chakraborty and Y. Sahai: Ironmaking Steelmaking, 19 (1992), 488.

21) B. F. Launder and D. B. Spalding: Comput. Methods Appl. Mech. Eng., 3 (1974), 269.

22) M. Barrios and S. W. Van Sciver: Cryogenics, 55-56 (2013), 12.

23) W. Na and P.-H. Zou: J. Harbin Inst. Tech., 14 (2007), 375.

24) S. V Patankar and D. B Spalding: Int. J. Heat Mass Transf., 15 (1972), 1787.

25) D.-A. Da: Vacuum Design Manual, National Defense Industry Press, Beijing, (1995), 226 (in Chinese). 